\title{
INFLUÊNCIA DA LÂMINA DE IRRIGAÇÃO NO CULTIVO DE GIRASSOL
}

\author{
Catariny Cabral Aleman ${ }^{1}$, Roberta Bertipaglia ${ }^{2}$ \\ ${ }^{1}$ Universidade Federal de Viçosa - UFV, Departamento de Engenharia Agrícola, Viçosa, MG. ${ }^{2}$ Universidade do Oeste Paulista - \\ UNOESTE, Presidente Prudente, SP. E-mail: catariny@ufv.br
}

\section{RESUMO}

O girassol é uma cultura rústica que apresenta baixa eficiência do uso da água, sendo necessário definir o manejo de irrigação adequado para aumentar a viabilidade de seu cultivo. A água é imprescindível para o correto funcionamento das atividades metabólicas das plantas que refletem principalmente na morfologia. A irrigação é uma técnica importante para atender as necessidades hídricas das plantas de forma racional e sustentável, aumentando a produtividade das culturas. 0 objetivo desse trabalho foi avaliar os efeitos de diferentes lâminas de irrigação no cultivo de girassol. O experimento foi conduzido em vasos alocados em bancada e ambiente telado no campus II na Universidade do Oeste Paulista, Presidente Prudente-SP. O delineamento experimental foi em bloco ao acaso, sendo 5 lâminas de irrigação (50\%, 75\%, 100\%, 125\% e 150\% da evapotranspiração da cultura - ETc) e 4 repetições, totalizando 20 parcelas. Para determinar as lâminas de irrigação foi utilizado o método de Penman-Monteith recomendado pela FAO. Foram determinados os seguintes parâmetros: a altura das plantas, o diâmetro da inflorescência, o número de folhas, a massa seca de parte aérea, a massa seca da inflorescência, o comprimento de raiz, a massa seca de raiz e relação raiz/parte aérea. A lâmina de irrigação de 125\% ETc apresentou os maiores valores para massa seca de parte e raiz, e comprimento de raiz. Para a produção, a lâmina de irrigação de $100 \%$ ETc atendeu as necessidade hídricas do girassol, favorecendo a formação do capítulo floral. Dessa forma, recomenda-se a lâmina de irrigação de $100 \%$ ETc para a produção de girassol em vaso para as condições climáticas de Presidente Prudente.

Palavras-chave: Helianthus annuus; eficiência do uso da água; necessidade hídrica.

\section{DEPTH OF IRRIGATION INFLUENCE IN SUNFLOWER CROP}

\section{ABSTRACT}

The sunflower is a rustic culture that has low efficiency of water use being necessary to define appropriate management of irrigation to increase the viability of its cultivation. The water is essential for the proper functioning of the metabolic activities of plants reflecting mainly in morphology. Irrigation is an important technique to meet the water needs of plants in a rational and sustainable manner, increasing crop productivity. The aim of this study was to evaluate the effects of different irrigation levels in sunflower cultivation. The experiment was conducted in pots allocated bench and greenhouse environment on campus II at the Universidade do Oeste Paulista, Presidente Prudente -SP. The experimental design was a randomized block, with 5 dephts of irrigation (50 \%, $75 \%, 100 \%, 125 \%$ and $150 \%$ of crop evapotranspiration - ETc) and 4 repetitions, totaling 20 plots. To determine the irrigation levels we used the Penman -Monteith method recommended by FAO. The parameters were determined: plant height, the diameter of the flower, the number of leaves, dry mass of shoot, dry mass of the inflorescence, root length, root dry weight and root/shoot. The water depth of $125 \%$ ETc showed the highest values for dry matter and root, and root length. The production of the depth of irrigaton $100 \%$ ETc water met the sunflower need, favoring the formation of floral chapter. Thus, it is recommended the depth of irrigation of $100 \%$ ETc for the production of potted sunflower to the climatic conditions of Presidente Prudente.

Keywords: Helianthus annuus ; water use efficiency; water requirement.

\section{INTRODUÇÃO}

O suprimento de água para a planta é resultante da interação solo, planta e atmosfera. A influência destes componentes torna o sistema dinâmico de tal forma que seja atendida a necessidade hídrica da cultura. A granulometria, a porosidade, a concentração da matéria orgânica e o potencial da água no solo são características que estão diretamente relacionadas à retenção e armazenamento de água. Estes fatores interferem diretamente nas decisões de manejo de irrigação para atender a demanda hídrica da cultura, de maneira a proporcionar a produção ótima do ponto de vista econômico. A irrigação deve repor a água retirada pela cultura no momento em que a disponibilidade de água no solo atingir o valor mínimo, abaixo do qual a planta começa a sentir 
os efeitos da restrição hídrica (SHOCK; WANG, 2011).

O conhecimento de áreas irrigadas e suas distribuições geográficas permitem o uso mais racional da água, sendo fundamental para o planejamento e gestão dos recursos hídricos do país. O Brasil apresenta atualmente cerca de 4,45 milhões de hectares irrigados. No mundo a irrigação chega a ocupar aproximadamente 17\% de toda a terra agricultável e responde por mais de $40 \%$ de todo alimento consumido. A utilização de irrigação para culturas agrícolas é uma prática utilizada para complementar a disponibilidade da água fornecida naturalmente pela precipitação, tornar produtivas as regiões áridas e semiáridas, proporcionando ao solo teor de umidade suficiente para suprir as necessidades hídricas das plantas (SETTI et al., 2001; LOPES et al., 2008).

O manejo de irrigação consiste no emprego racional da água com o objetivo de atender as necessidades hídricas das plantas elevando a produção e a eficiência do uso da água. Pode ser baseado na evapotranspiração relacionando o consumo de água pela planta e na umidade do solo determinando parâmetros de estresse hídrico a partir do potencial matricial (SHOCK; WANG, 2011).

O girassol é uma cultura com ampla adaptabilidade em diferentes condições de clima e fotoperíodo. A produção principalmente com enfoque na bioenergia pode ser aumentada com o manejo adequado da água de irrigação, utilizando parâmetros relacionados à evapotranspiração e coeficientes de cultura por fase de desenvolvimento. Viana et al. (2012) estudaram a cultura do girassol irrigado e verificaram que a altura da planta, diâmetros do caule, número de folhas e a produtividade aumentou linearmente em função das lâminas de irrigação de 0,$25 ; 0,50 ; 0,75 ; 1,0$ e 1,25 da Evapotranspiração do Tanque Classe " $A$ " (ECA).
Considerando a importância de definir a lâmina de irrigação ótima para a maior produtividade, o objetivo desse trabalho foi avaliar os efeitos de diferentes lâminas de irrigação no cultivo de girassol cv. Bonito de Outono Sortido.

\section{MATERIAL E MÉTODOS}

O experimento foi conduzido em ambiente telado no campus II, na Universidade do Oeste Paulista, Presidente Prudente - SP, localizada na Rodovia Raposo Tavares km 572, a uma latitude de $22^{\circ} 07^{\prime} 04^{\prime \prime} \mathrm{S}$ e longitude de $51^{\circ} 22^{\prime} 04^{\prime \prime} \mathrm{W}$, aproximadamente a 432 metros acima do nível do mar. O clima da região é caracterizado, segundo Köppen, como AW mesotérmico, com verões quentes e invernos secos. O solo é classificado como Argissolo Vermelho - Amarelo, Eutrófico de textura arenosa/média (EMBRAPA, 1999). O delineamento experimental foi em bloco ao acaso, sendo 5 tratamentos com lâminas de irrigação com 4 repetições, totalizando 20 parcelas. $O$ experimento foi conduzido entre 2 de junho a 16 de setembro de 2014.

Foram utilizadas sementes de girassol cv. Bonito de Outono Sortido ISLA ${ }^{\circledast}$. As sementes foram plantadas em vasos de PVC com dimensões de $20 \mathrm{~cm}$ de altura $\times 20 \mathrm{~cm}$ de diâmetro.

As lâminas de irrigação foram: 150\%, $100 \%, 75 \%, 50 \%$ e $25 \%$ da evapotranspiração da cultura (ETc). A irrigação foi conduzida com auxílio de proveta e regador sendo estabelecido turno de rega semanal. As lâminas de irrigação foram determinadas pela equação de PenmanMonteith recomendada pela FAO (equação 01, 02, 03, 04 e 05) e utilizando o coeficiente de cultura $(\mathrm{kc})$ de 1,15 (CAVALCANTE JUNIOR, 2011).

$$
\text { ETo }=\frac{0,408 . s .(R n-G)+\gamma \cdot 900 \cdot U_{2}\left[\frac{\text { es-ea }}{\mathrm{Td}+273}\right]}{\mathrm{s}+\gamma \cdot\left(1+0,34 \cdot \bigcup_{2}\right)}
$$

Sendo: ETo- evapotranpiração de referência $\left(\mathrm{mm} \mathrm{dia}^{-1}\right)$; $\mathrm{Rn}$ - radiação líquida total diária $\left(\mathrm{MJ} \mathrm{m}^{-2} \mathrm{dia}^{-1}\right)$; G- fluxo total

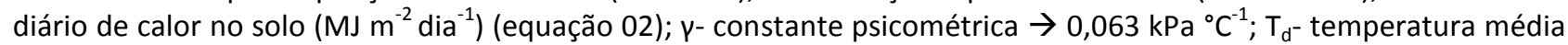
diária $\left({ }^{\circ} \mathrm{C}\right) ; \mathrm{U}_{2}$ - velocidade do vento $\left(\mathrm{m} \mathrm{s}^{-1}\right) ; \mathrm{e}_{\mathrm{s}}$ - pressão de saturação de vapor ( $\mathrm{kPa}$ ) (equação 3); $\mathrm{e}_{\mathrm{a}}$ - pressão parcial de vapor ( $\mathrm{kPa})$ (equação 4); s- taxa de variação da pressão de vapor em relação à temperatura $\left(\mathrm{kPa}{ }^{\circ} \mathrm{C}^{-1}\right)$.

$$
\mathrm{G}=0,38 .\left(T_{d}-T_{3 d}\right)
$$




$$
\begin{aligned}
& \mathrm{e}_{\mathrm{s}}=\frac{\left\{0,6108 \cdot \mathrm{e}^{[(17,27 . T \text { máx }) \div(237,7+T \text { máx })]}+0,6108 \cdot \mathrm{e}^{[((17,27 . T \text { mín }) \div(237,7+T \text { mín })]}\right\}}{2} \text { (equação 03) } \\
& \mathrm{e}_{\mathrm{a}}=(\underline{\text { UR.e }} \mathrm{e}) \\
& 100 \\
& \mathrm{~S}=\frac{\text { 4098.es }}{(\mathrm{T}+237,2)^{2}}
\end{aligned}
$$

Foram determinados: a altura das plantas, o diâmetro da inflorescência, o número de folhas, a massa seca de parte aérea, a massa seca da inflorescência, o comprimento de raiz, a massa seca de raiz e relação raiz/parte aérea. Os parâmetros avaliados foram submetidos ao teste $\mathrm{F}$ e posteriormente ao teste de Scott-Knott ao nível de probabilidade de $5 \%$ para comparação entre as médias.

\section{RESULTADOS E DISCUSSÃO}

Foi possível observar para as alturas de planta (Figura 1) que durante o desenvolvimento do girassol a lâmina de irrigação de $125 \%$ ETc resultou em maior crescimento. Aos 14 dias após a emergência (DAE) a lâmina de irrigação de $100 \%$ ETc resultou em maior crescimento junto a lâmina de $125 \%$ ETc.

Verificou-se que para a variável altura a lâmina de irrigação de $100 \%$ ETc foi suficiente para atender a demanda hídrica durante o período experimental, ou seja, embora a lâmina de irrigação de $125 \%$ ETc tenha apresentado valores de altura maior, ambas foram estatisticamente iguais.
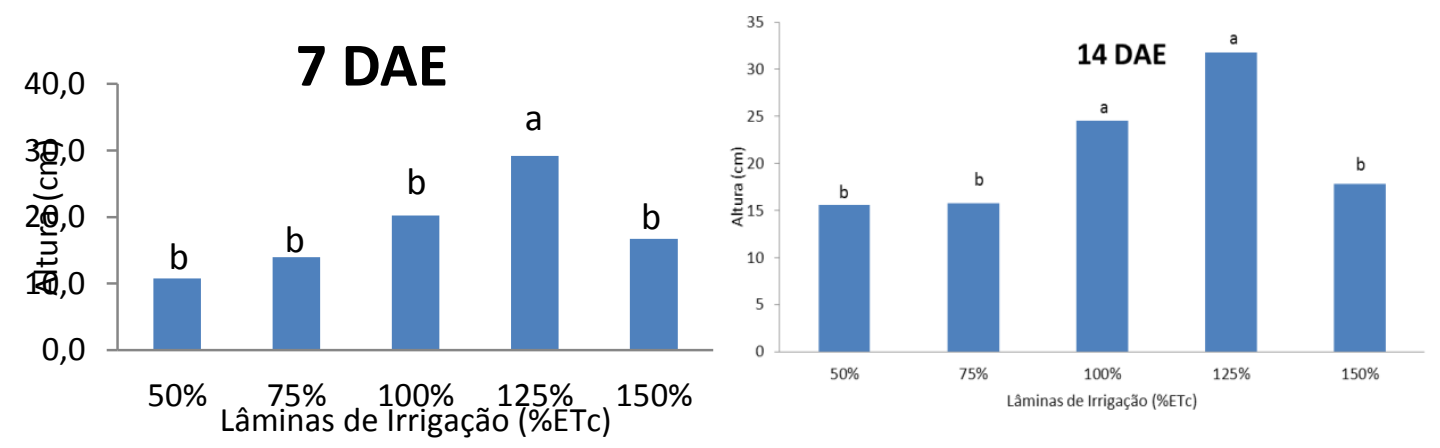

21 DAE
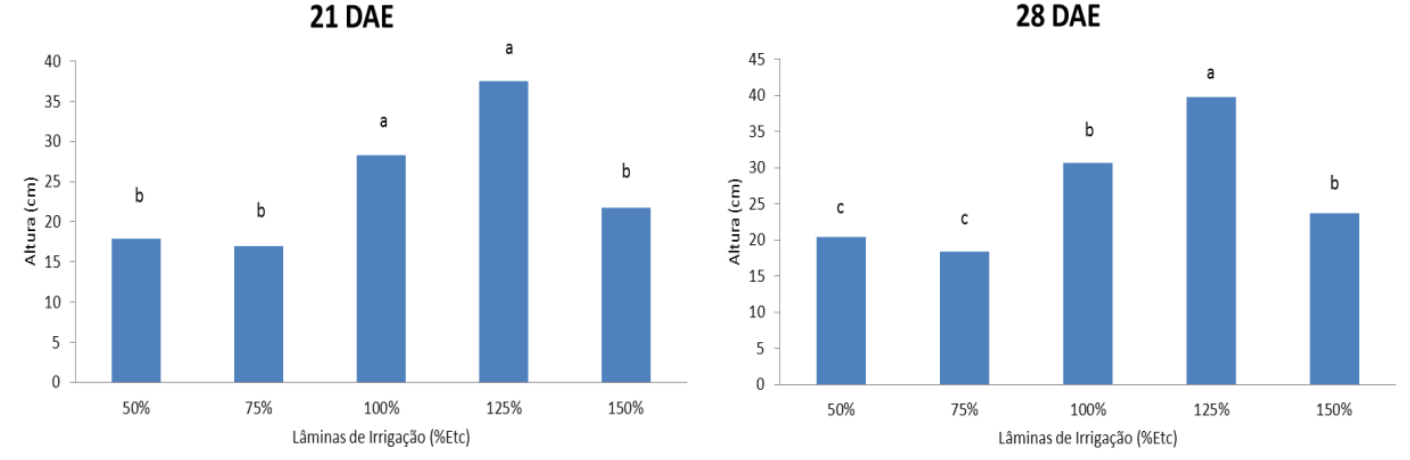
35 DAE

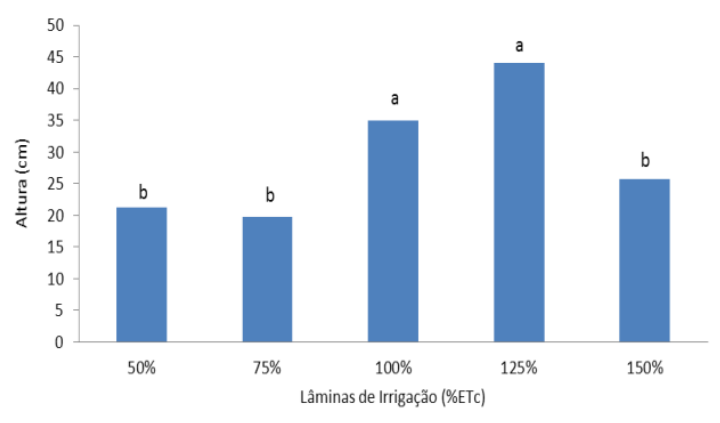

49 DAE

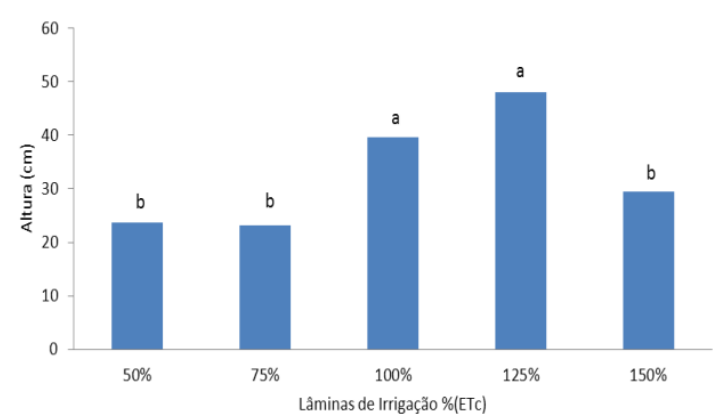

42 DAE

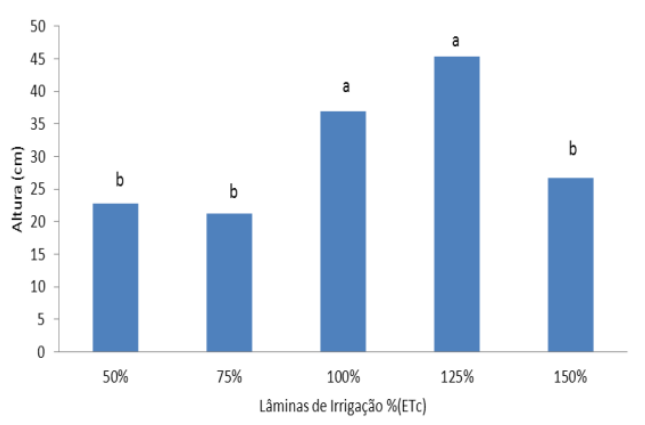

56 DAE

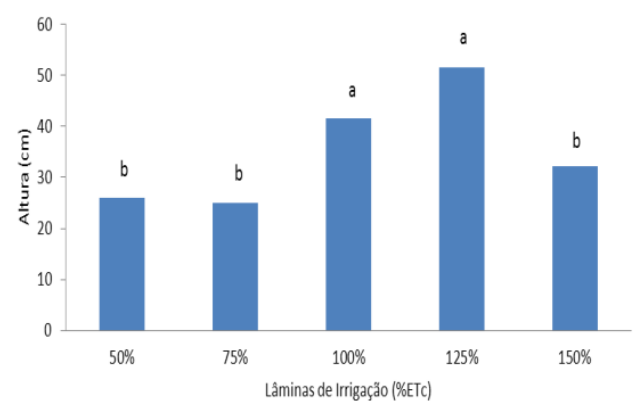

Figura 1. Altura aos 7, 14, 21, 28 dias após a emergência (DAE) do girassol submetido à diferentes lâmina de irrigação: 50, 75, 100, 125 e 150\% ETc.

Para o diâmetro de capítulos florais (Figura 2A) e a produção (Figura 2B), observou-se que apenas as lâminas de irrigação de $100 \%$ e $125 \%$ ETc produziram capítulos florais. As condições de déficit e excesso hídrico podem prejudicar a produção causando abortamento de capítulos florais ou estendo o desenvolvimento vegetativo sem que ocorra produção de capítulos florais. Considerando o diâmetro de capitulo floral a lâmina de irrigação de $125 \%$ ETc resultou no maior diâmetro embora estatisticamente não diferiu de $100 \%$ ETc. Em decorrência da reduzida precipitação ocorrida durante todo período experimental, a planta requereu sua máxima necessidade hídrica designada pela lâmina de $100 \%$ ETc (sem déficit ou excesso hídrico).
A

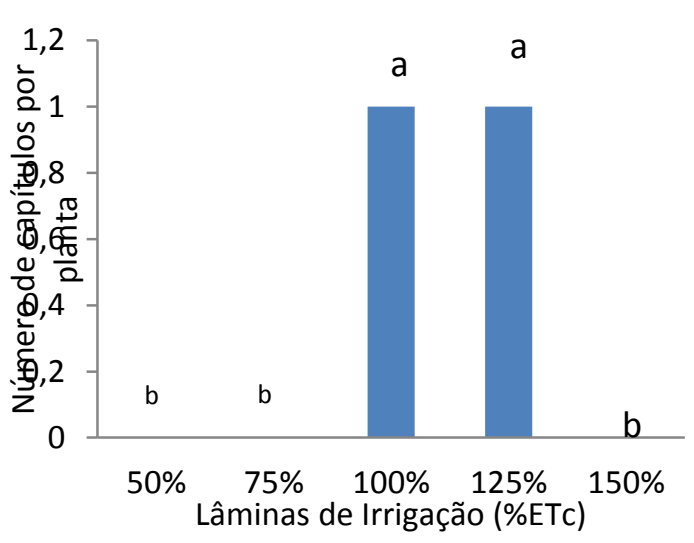

B

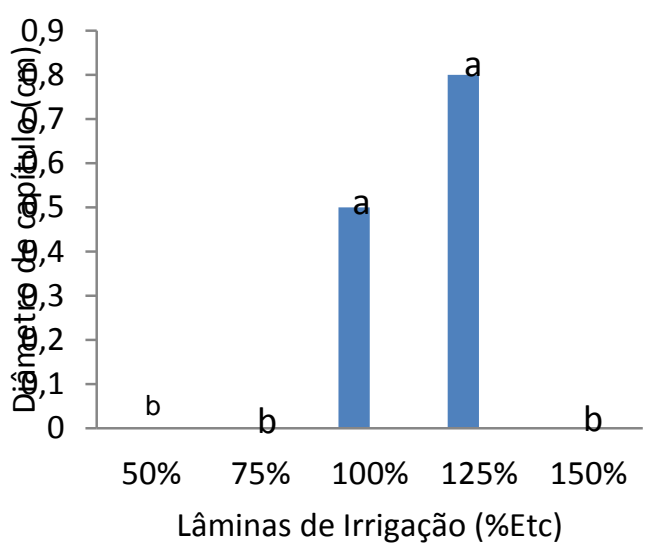

Figura 2. Número de capítulos e diâmetro de capítulo $(\mathrm{cm})$ do girassol submetido à diferentes lâmina de irrigação: 50, 75, 100, 125 e 150\% ETc.

De acordo com a Figura 3, a massa seca de parte aérea foi superior para a lâmina de irrigação de 
$125 \%$ ETc. As lâminas de irrigação com déficit e excesso hídrico apresentaram o menor acúmulo de massa seca de parte aérea.

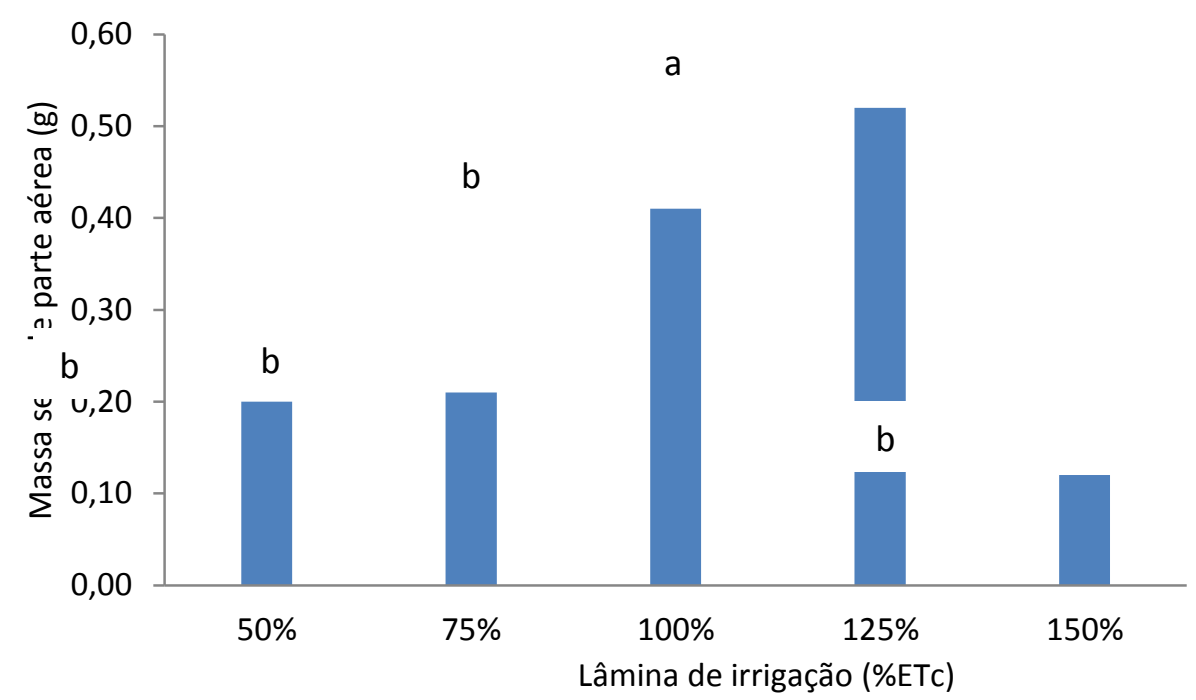

$\mathrm{p}$

Figura 3. Massa seca de parte aérea do girassol submetido à diferentes lâmina de irrigação: 50, 75, 100, 125 e $150 \%$ ETc.

$\mathrm{Na}$ Figura 4, observou-se que para comprimento de raiz a lâmina de irrigação de $150 \%$ ETc apresentou o maior comprimento. Para este tratamento (excesso hídrico) as plantas realocaram os fotoassimilados para desenvolvimento de raiz e reduzindo acúmulo de massa seca de parte aérea.
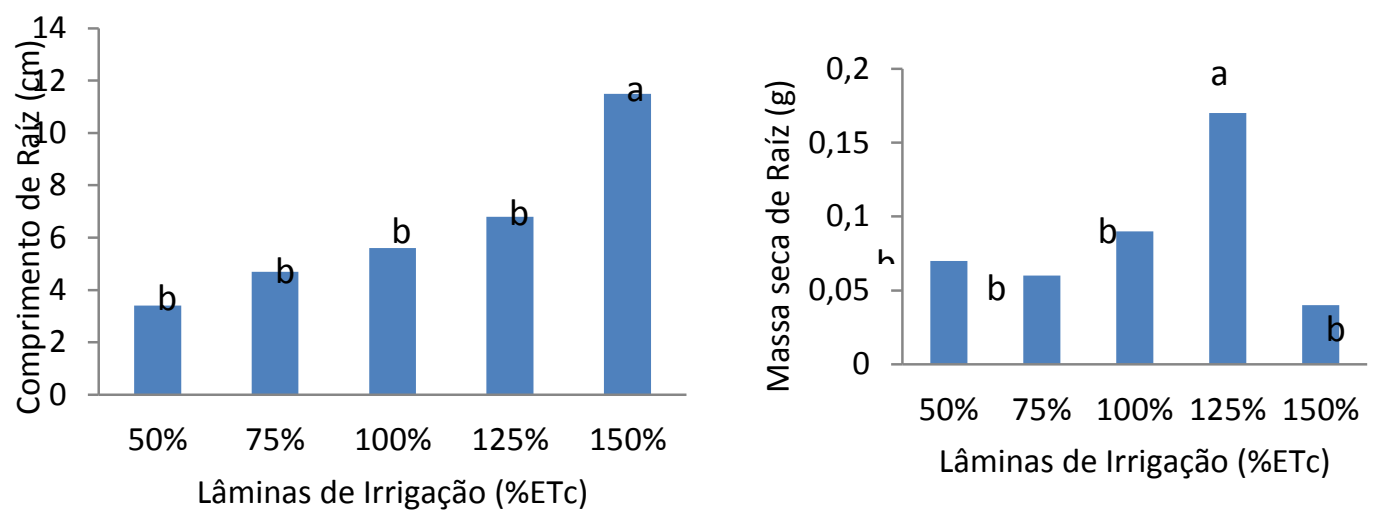

Figura 4. Comprimento de raiz $(\mathrm{cm})$ e massa seca de raiz $(\mathrm{g})$ do girassol submetido à diferentes lâmina de irrigação: 50, 75, 100, 125 e 150\% ETc.

A relação raiz/parte aérea (Figura 5) foi superior para a lâmina de irrigação de $100 \%$ e $125 \%$ ETc. O aumento no fornecimento de água as plantas favoreceu o desenvolvimento radicular e detrimento ao menor desenvolvimento da parte aérea (caule+folhas). A redistribuição de fotoassimilidados resultou na elongação do sistema radicular e formação do órgão reprodutivo. Geralmente, em situações de estresse hídrico ocorre aumento do volume do sistema radicular como alternativa para sobrevivência, reduzindo a produção e biomassa de parte aérea (TAIZ; ZEIGER, 2009), situação divergente a ocorrida neste experimento. 


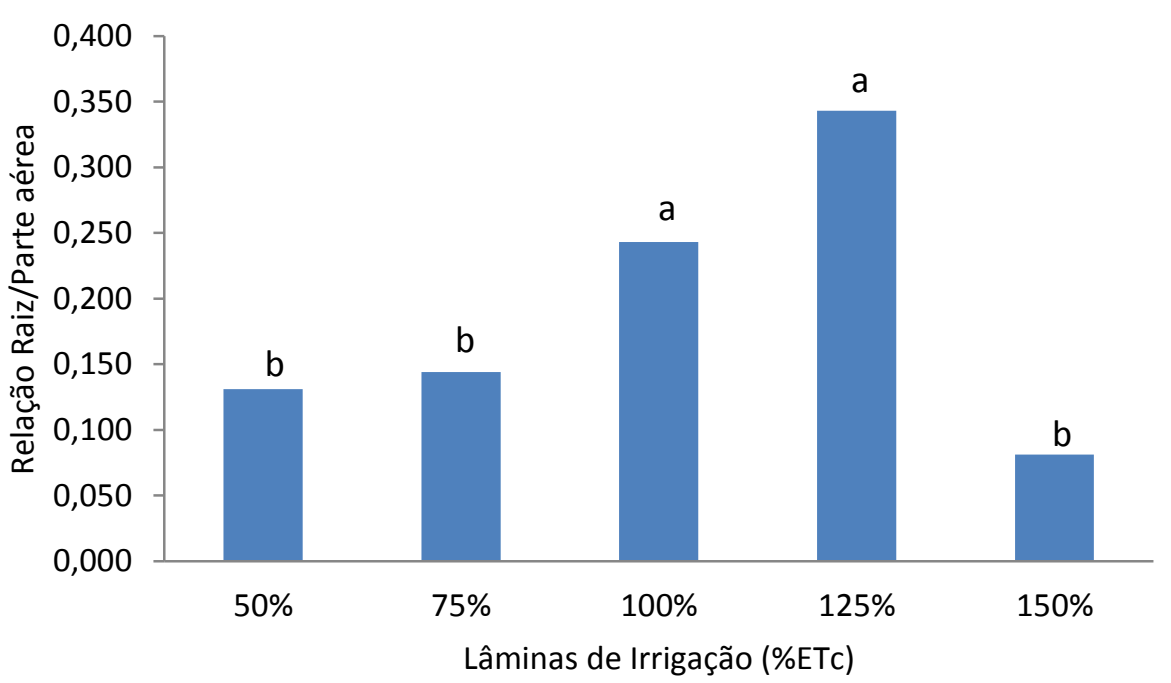

Figura 5. Relação raiz/parte aérea do girassol submetido à diferentes lâmina de irrigação: 50, 75, 100, 125 e $150 \%$ ETc.

Segundo Silva et al. (2007) que avaliaram diferentes lâminas de água aplicadas na cultura do girassol nos híbridos Hélio 250 e Hélio 251, concluíram que a altura da planta varia devido a quantidade de água fornecida pela lâmina de irrigação, aumentando linearmente. Justificando a eficiência da lâmina de $100 \%$ ETc e $125 \%$ ETc, resultando em maior crescimento das plantas submetidas a esses tratamentos.

O maior diâmetro apresentado pelas raízes de plantas submetidas a maiores lâminas de água pode ser comparado aos resultados obtidos por Nezami et al. (2008), que verificaram redução de 20 a $46 \%$ no diâmetro do coleto de plantas de girassol em déficit hídrico.

Castro et al. (2010) verificaram redução de massa seca total para plantas em estresse hídrico comparada com plantas sem estresse hídrico. Silva et al. (2007) afirmaram também ter alcançado maior biomassa para os maiores níveis de água.

Segundo Gomes et al. (2003), os menores diâmetros florais foram obtidos em tratamentos não irrigados. Quando comparado aos resultados obtidos nota-se que a lâmina de $125 \%$ ETc apresentou o maior diâmetro de capítulo floral. A formação e o tamanho de capítulos florais possui relação direta com o fornecimento de água a planta.

Considerando a importância econômica da produção de capítulos florais para a cultura do girassol, recomenda-se para a região do Oeste Paulista a lâmina de irrigação de $100 \%$ ETc.

\section{REFERÊNCIAS}

CASTRO, C.; MOREIRA, A.; OLIVEIRA, R.F.; DECHEN, A.R. Boro e estresse hídrico na produção do girassol. Ciência e Agrotecnologia, v. 30, n. 2, 2010.

CAVALCANTE JUNIOR, E.G. Produção e necessidade hídrica do girassol irrigado na Chapada do Apodi. 2011. 61p. Dissertação (Mestrado) - Universidade Federal Rural do Semiárido, Mossoró-CE.

EMBRAPA. Centro Nacional de Pesquisa de Solos (Rio de Janeiro, RJ). Sistema brasileiro de classificação de solos. Brasília, DF: Embrapa Produção da Informação, 1999. 412 p.

GOMES, E.M.; UNGARO, M.R.G.; VIEIRA, D.B. Impacto da suplementação hídrica no acúmulo e partição da matéria seca de girassol. In: $3^{\circ}$ Simpósio Nacional de Girassol, $15^{\circ}$ Reunião Nacional da Cultura de Girassol, 2003. Anais... Ribeirão Preto: CATI, 2003, CD-Rom.

LOPES, J.F.; ANDRADE, E.M.; CHAVES, L.C.G. Impacto da irrigação sobre os solos de perímetros irrigados na Bacia do Acaraú, Ceará, Brasil. Engenharia Agrícola, v. 28, n. 1, p. 34-43, 2008. http://dx.doi.org/10.1590/S010069162008000100004

NEZAMI, A.; KHAZAEI, H.R.; BOROUMAND REZAZADEH, Z.; HOSSEINI, A. Effects of drought stress and defoliation on sunflower (Helianthus annuus) in controlled conditions. Desert, v. 1, p. 99-104, 2008.

SETTI, A.A.; LIMA, J.E.F.W.; CHAVES, A.G.M.; PEREIRA, I.C. Introdução ao gerenciamento de recursos hídricos. Brasília: Agência Nacional de 
Energia Elétrica: Agência Nacional de Águas, 2001.

SHOCK, C.C.; WANG, F.X. Soil water tension, a powerful measurement for productivity and stewardship. Hortscience, v.46, n.2, p.178-185, 2011.

SILVA, M.L.O.; FARIA, M.A.; REIS, R.P.; SANTANA, M.J.; MATTIOLI, W. Viabilidade técnica e econômica do cultivo de safrinha do girassol irrigado na região de Lavras, MG. Ciência e Agrotecnologia, v. 31, n. 01, p. 200-205, 2007. http://dx.doi.org/10.1590/S1413-

70542007000100029

TAIZ, L.; ZEIGER, E. Fisiologia vegetal. 4. ed. Porto Alegre: Artmed, 2009.

VIANA, T.V.A.; LIMA, A.D.; MARINHO, A.B.; DUARTE, J.M.L.; AZEVEDO, B.M.; COSTA, S.C. Lâminas de irrigação e coberturas do solo na cultura do girassol, sob condições semiáridas. Irriga, v.17, p.126-136, 2012. http://dx.doi.org/10.15809/irriga.2012v17n2p12 6 